في اطار التعاون بين مركز تطوير التعليم الجامعي وكلية التربية جامعة عين شمس

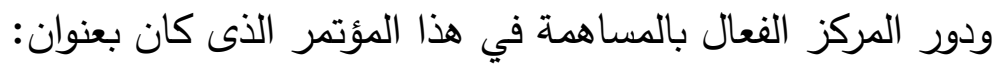

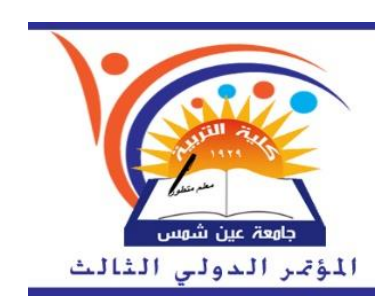

المؤتمر الدولي الثالث لكلية التربية جامعة عين شمس الته "رؤى مستقبلية لتطوير التعليم وإعداد المعلم"

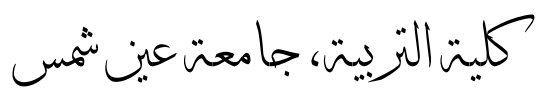

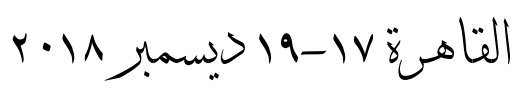

$$
\begin{aligned}
& \text { تحت رعاية }
\end{aligned}
$$

أ.دد/عبد الوهاب عزت

ريس جاموة عين ثممن

رئيس المؤتمر

أ.د. ماجد أبو العنين

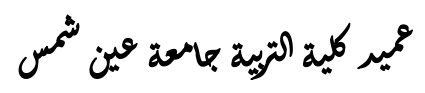

\section{أمين المؤتمر}

أ.د/صفاء عفيفي

اوستاذ ع الثنس التربوي

كلية اتريّة بامعة حين اثمنى
مقرر المؤتمر

$$
\text { أ.د/حازم راشد }
$$

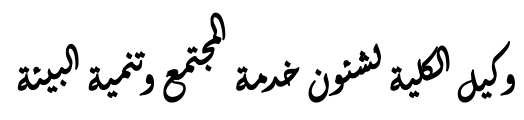

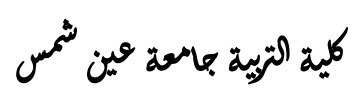


المحور الأول: رؤى مستقبلية لدور التعليم في مواجهة التحديات المحلية:

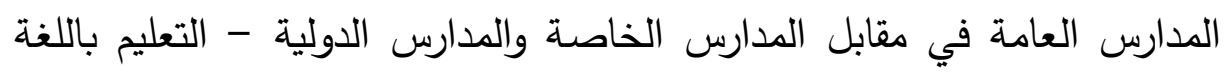

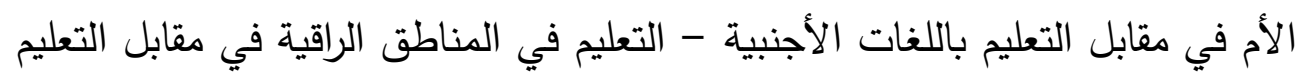

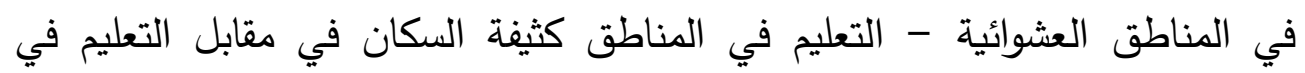

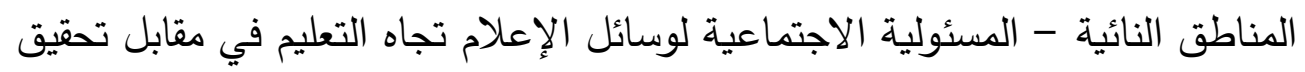

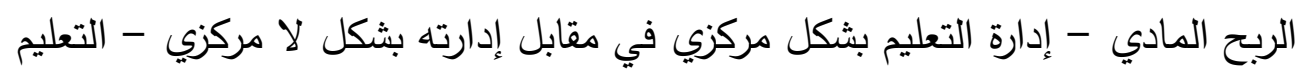
الديني في مقابل التعليم المدني.

المحور الثاني: رؤى مستقبلية للتعليم في مناطق الأزمات والنزاع:

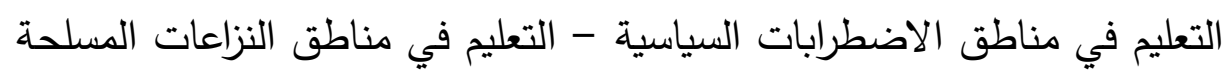

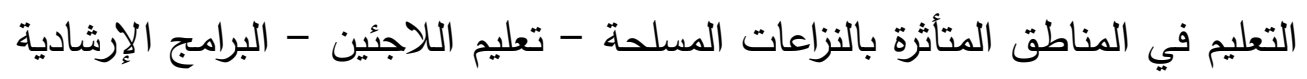
للأطفال فيما بعد الصدمة - التعليم في مناطق الكوارث الطبيعية. المحور الثالث: رؤى مستقبلية للتعليم غير التقليدي مدار STEM - المدارس الافتراضية على شبكة الإنترنت - المدارس الدامجة لذوي الاحتياجات الخاصة - مدارس التعليم المجتمعي - المدارس ثنائية اللغة.

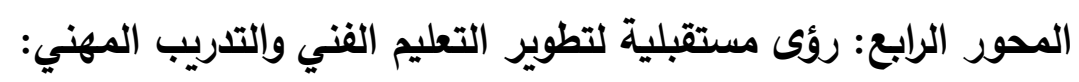

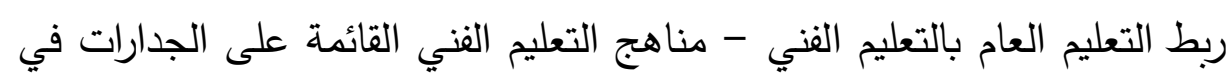

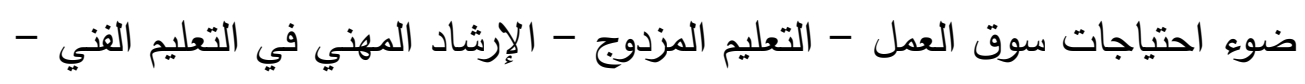

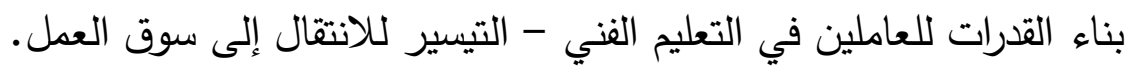

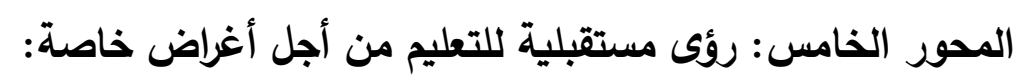

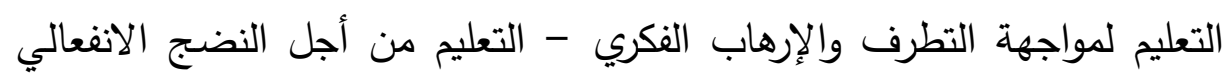
والوجداني - التعليم من أجل ريادة الأعمال - التعليم من أجل حقوق الإنيم الإنسان - 
التعليم للقضاء على التمييز - التعليم من أجل تتمية الوعي السياسي - التعليم للحفاظ على البيئة والصحة والسكان.

\section{المحور السادس: رؤى مستقبلية لتحقيق التميز في التعليم:}

المصادر غير التقليدية لتمويل التعليم - شبكات النمو المهني الخاصة بالمعلمين - مناهج تتمية الإبداع الفكري - المناهج البينية للتخصصات المتعددة - التقويم الفعلي لما يتعلمه الطلاب - الحوكمة في إدارة مؤسسات التعليم. المحور السابع: رؤى مستقبلية في إعداد المعلم: نظام الدراسة في برامج إعداد المعلم - اتجاهات عالمية جديدة في إعداد المعلم - تدويل برامج إعداد المعلم - الشراكة بين كليات التربية ومؤسسات المجتمع المدني - التنمية اللغوية في برامج إعداد المعلم - البحث التربوي في كليات التربية.

\section{رسوم التسجيل في المؤتمر وطرق الدفع}

\section{وكان برنامج المؤتمر كالتالي}

\begin{tabular}{|c|c|c|c|}
\hline \multicolumn{4}{|c|}{ 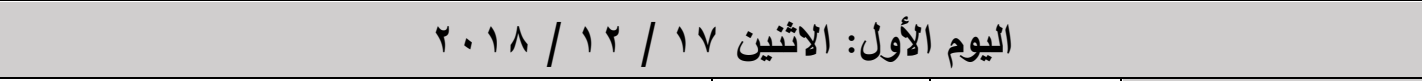 } \\
\hline عنوان الجلسة & إدارة الجلسة & المكان & التوقيت \\
\hline \multicolumn{2}{|l|}{ 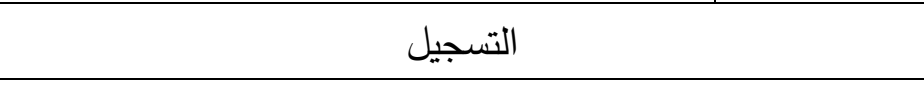 } & \multirow{4}{*}{ المسرح } & \\
\hline \multicolumn{2}{|c|}{ افتتاح المؤتمر بحضور السيد رئيس الجامعه والساده النواب } & & .... \\
\hline تعليم التحرير لا للتطويع & أسماعيل على سعيد & & \\
\hline \multicolumn{2}{|l|}{ استراحة شاي } & & • . 1الى •r:r| \\
\hline 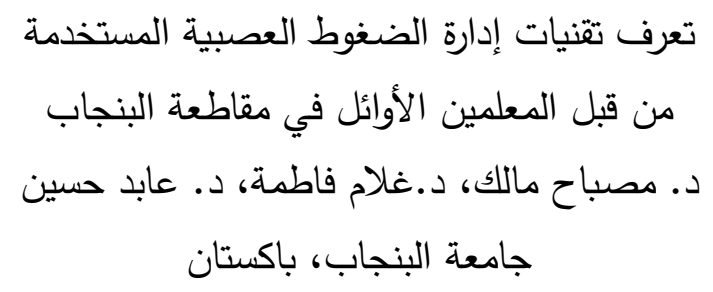 & 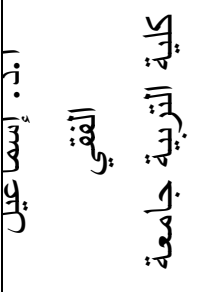 & 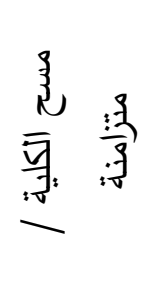 & 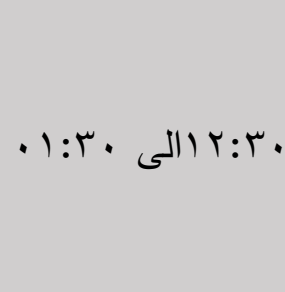 \\
\hline
\end{tabular}




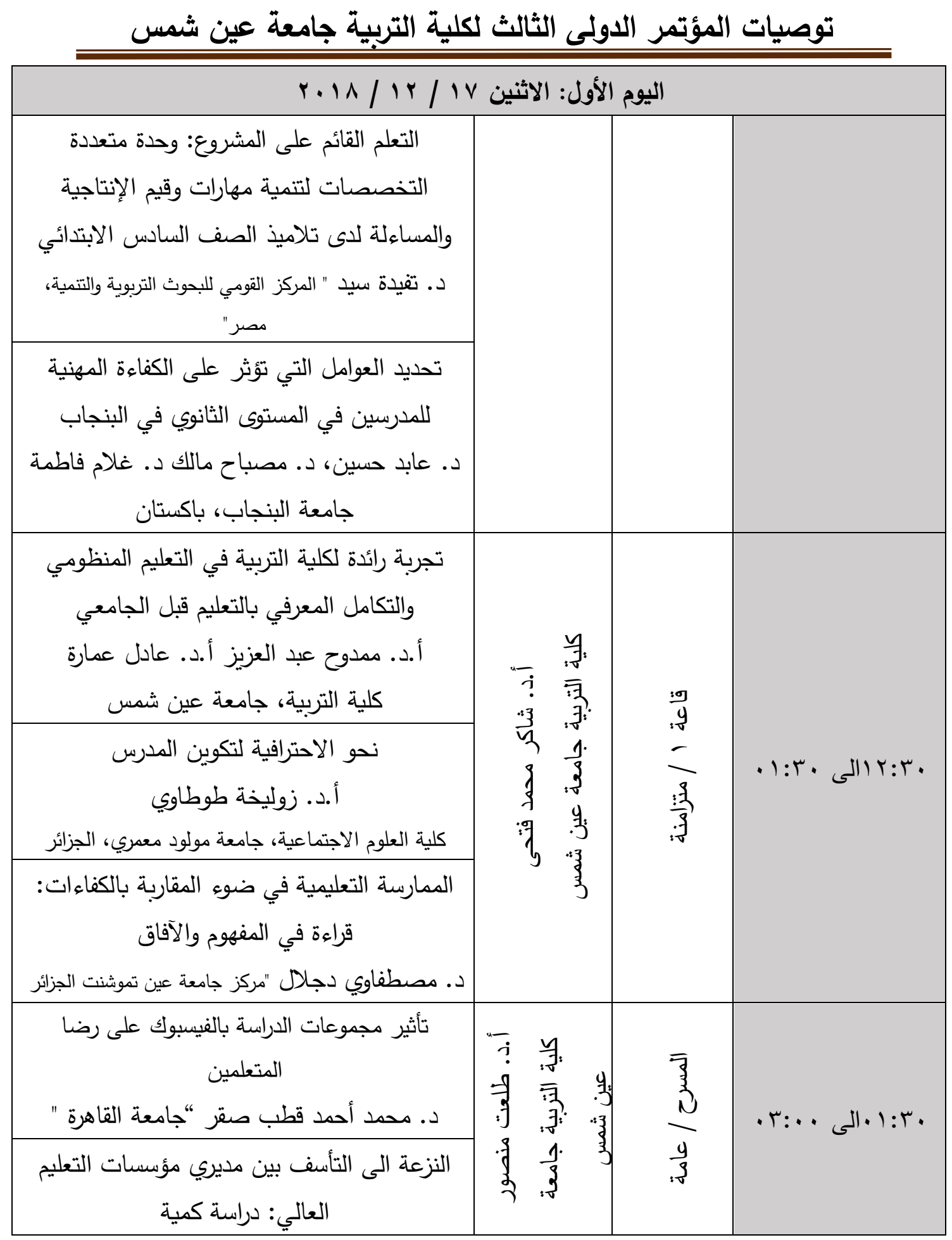


ا.د. ممتاز أختر ، د.مصباح مالك د. ر. غلام فاطمة جامعة البنجاب، باكستان

أثر التكنولوجيا ووسائل التواصل الاجتماعي على مهارات الاتصال التجاري لمتعلمي "اليوم الكبار"

$$
\text { د. بوب باريت }
$$

الجامعة العامة الأمريكية، الولايات المتحدة الأمريكية رضا الوالدين ومشاركتهم في توفير التعليم الخاص في مرحلة الطفولة المبكرة لأطفالهم مما يعانون لونيل من الاعاقة السمعية د. غلام فاطمة، د. مصباح مالك، كأك د. سمينة أشرف "جامعة البنجاب، باكستان"

الشراكة بين المدرسة والجامعة لمجتمعات من المتعلمينSUP4PCL مشروع إيراسموس كلية التربية جامعة عين شمس دراسة حالة

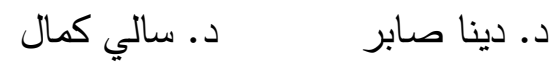

$$
\text { أد. مينة أبو المكارم }
$$

\begin{tabular}{|c|c|c|}
\hline غذاء & & 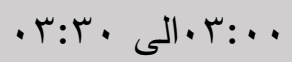 \\
\hline 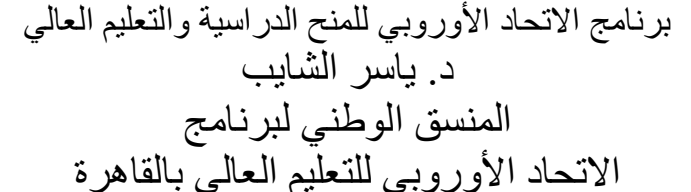 & 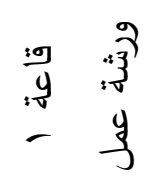 & •الى . ب:0. \\
\hline
\end{tabular}

معلمات بوزارة التربية والتعليم، مصر لهر لهر 


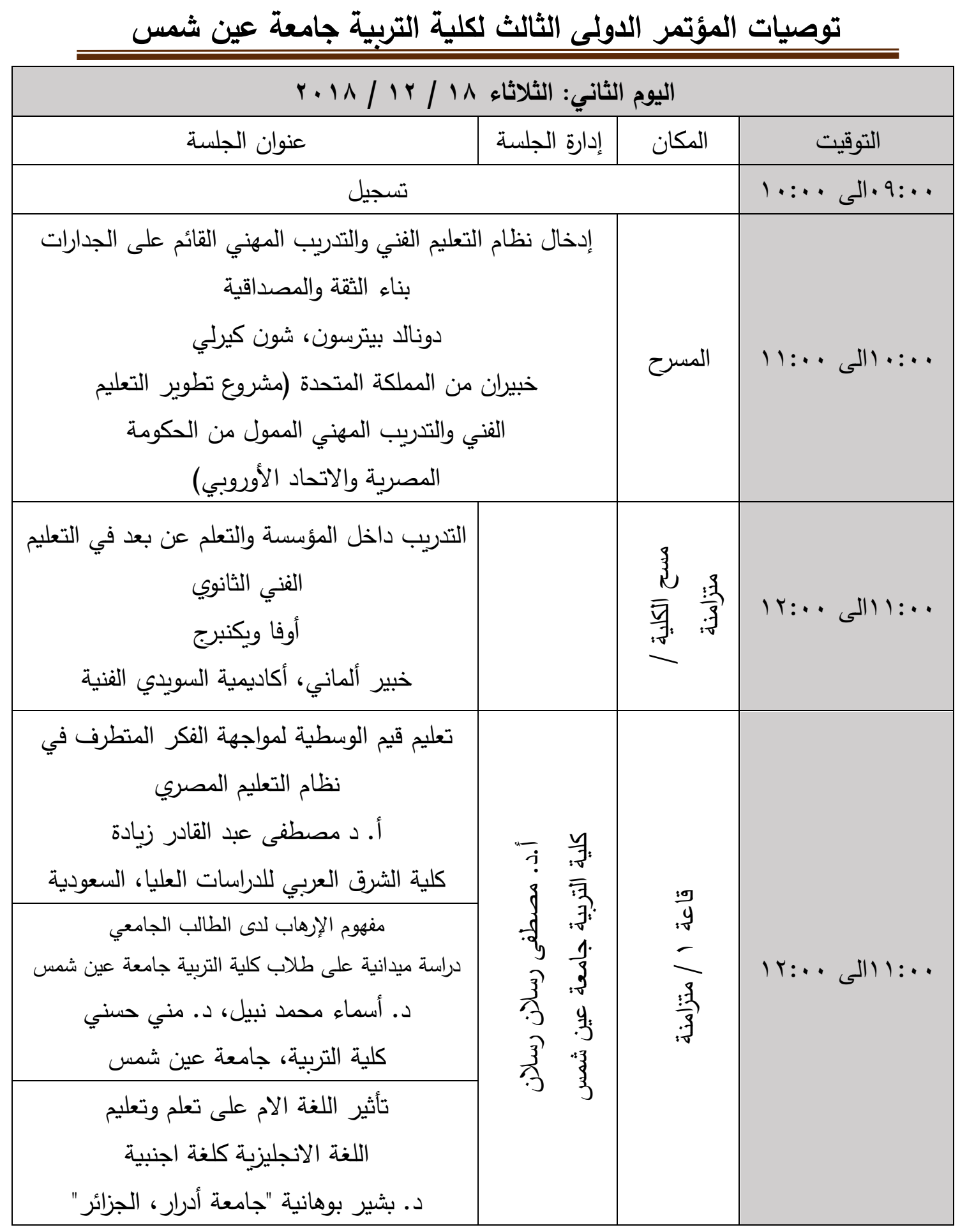




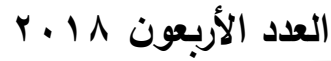

مجلة دراسات فى التعليم الجامعى

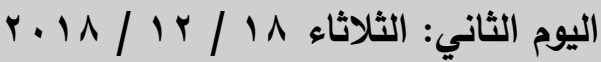

إثكالية جعل اللغة الأجنبية لغة التعليم وتداعيات

ذلك على الهوية الثقافية العربية

د. أيسم سعد محمدي محمود

كلية الدراسات العليا للتربية، جامعة القاهرة

\begin{tabular}{|c|c|c|c|}
\hline \multicolumn{3}{|l|}{ استراحة شاي } & 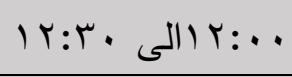 \\
\hline 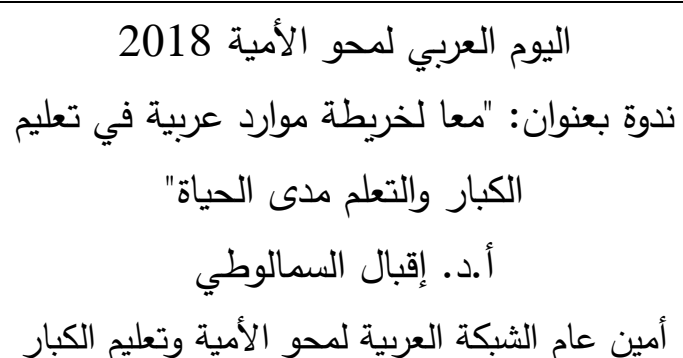 & \multirow{3}{*}{ 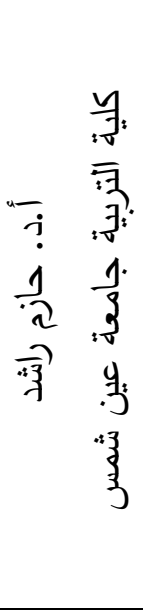 } & \multirow{3}{*}{$\frac{\overline{3}}{\frac{3}{3}}$} & \multirow[t]{3}{*}{ 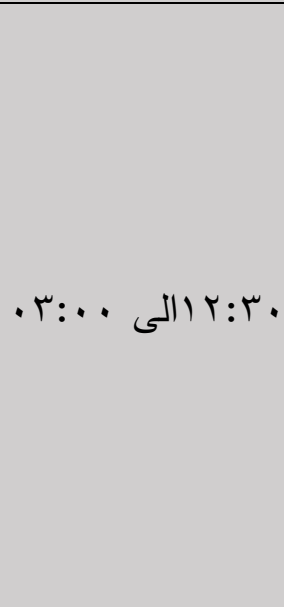 } \\
\hline عرض لأنشطة شركة "تميز لبناء القدرات" & & & \\
\hline تكريم الثبكة العربية لمحو الأمية ورعاة المؤتمر & & & \\
\hline \multicolumn{3}{|l|}{ غذاء } & • . . •الى • .r:T. \\
\hline 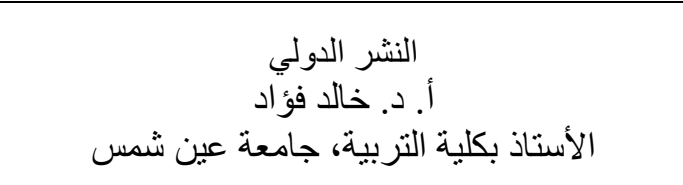 & & 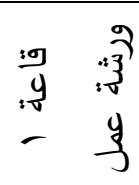 & 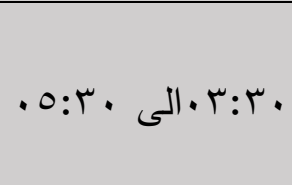 \\
\hline حفل موسيقي مصري & 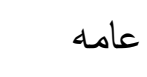 & & • . ب:0. \\
\hline
\end{tabular}




\begin{tabular}{|c|c|c|c|}
\hline \multicolumn{4}{|c|}{ 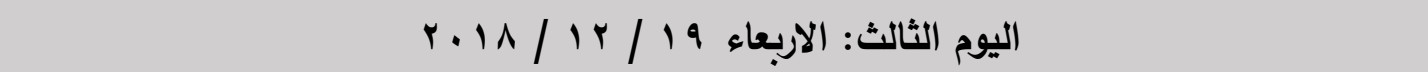 } \\
\hline عنوان الجلسة & إدارة الجلسة & المكان & التوقيت \\
\hline \multicolumn{2}{|l|}{ 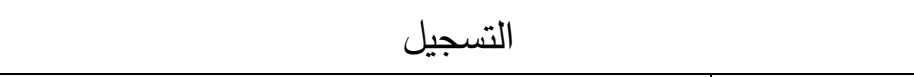 } & 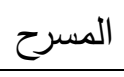 & \\
\hline 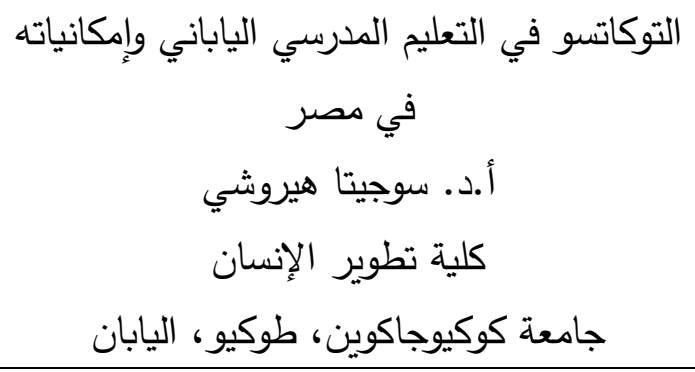 & \multirow{2}{*}{ 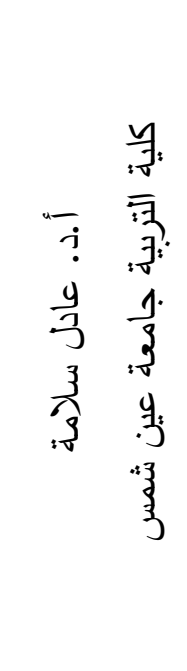 } & \multirow{2}{*}{ 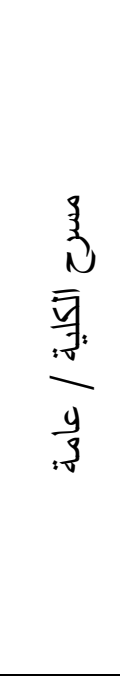 } & \multirow[t]{2}{*}{ 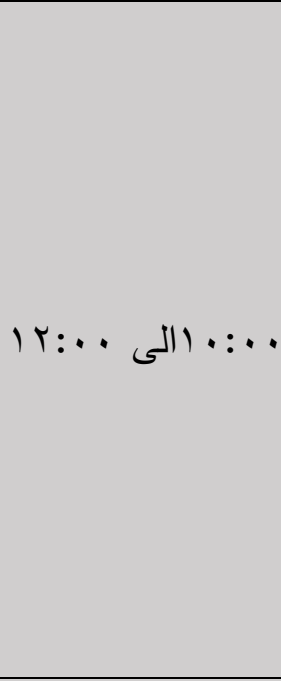 } \\
\hline 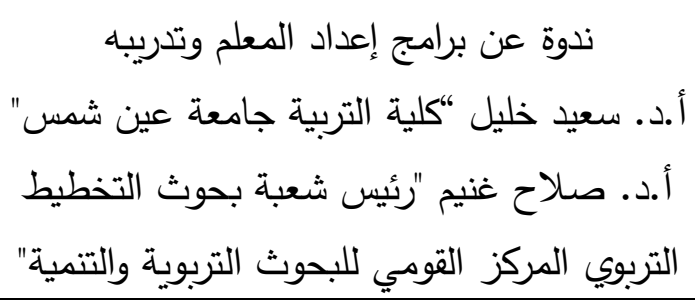 & & & \\
\hline \multicolumn{3}{|l|}{ استراحة شاي } & 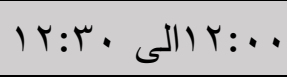 \\
\hline 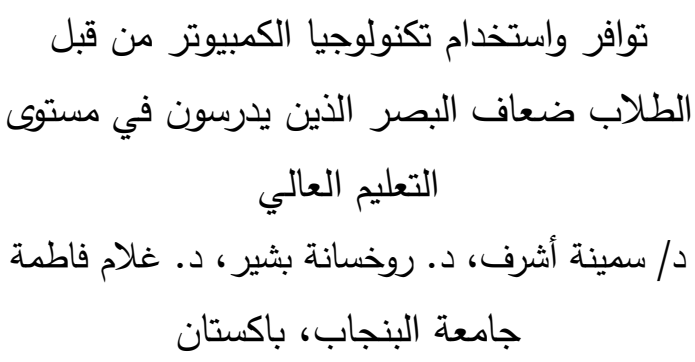 & 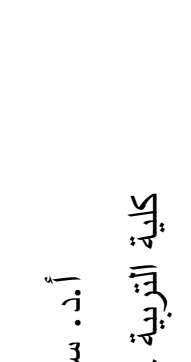 & $\bar{s}$ & \\
\hline 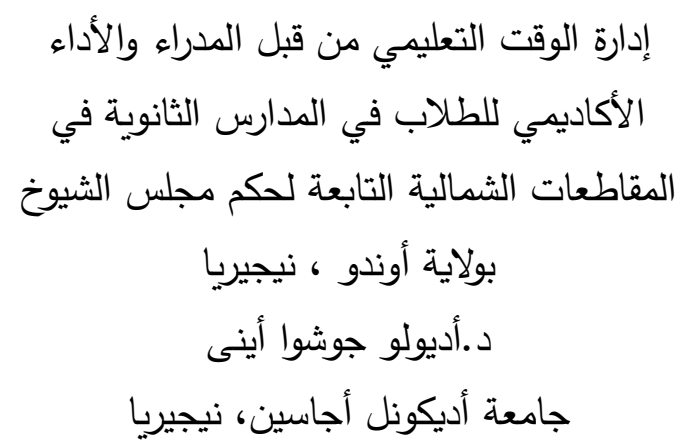 & 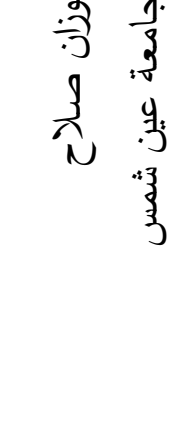 & $\frac{1}{9}$ & r r \\
\hline
\end{tabular}


بناء القدرة الانفعالية ، والتعلم بوعي ، والتمتع بالحياة من خلال تطوير ذكاء القلب لطلاب

كليات التربية (معلمو المستقبل) 1. إد/ صناء عفيفي

كلية التزبية جامعة عين شمس

فاعلية اساليب التحفيز الخاصة بمديري المدارس على أداء معلمي المدارس الابتدائية على اساس عمرهم د. سوميرة مونوار ، د. مصباح مالك لك لك د. غلام فاطمة، د. خديجة ستار جامعة البنجاب، باكستان

دراسة مقارنة للنهج التفاعلي والنهج المتمحور

حول المعلم لاكتساب المفردات

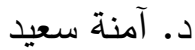

جامعة أي إي آر، باكستان

الإعاقة والاستبعاد الاجتماعي: خبرات الطلاب ذوي

الإعاقة السمعية الملتحقين بالمدارس الخاصة الإسراس

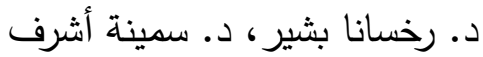
جامعة البنجاب، باكستان

مشكلات تقويم الأداء الوظيفي التي تواجهُ مديري مدارس محافظة الظاهرة في سلطنة عمان أ/سعيد بن راشد بن علي الشهومي وزارة التربية والتعليم، عمان د/ حسام الدين السيد محمد ابراهيم

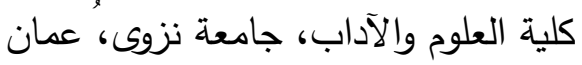




\begin{tabular}{|c|c|c|}
\hline \multicolumn{3}{|c|}{ 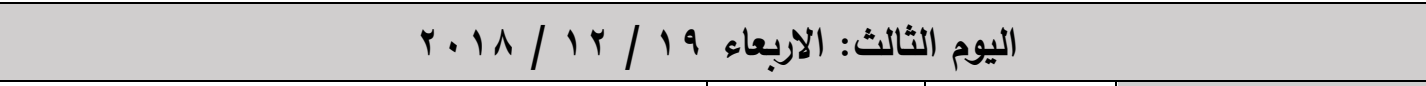 } \\
\hline 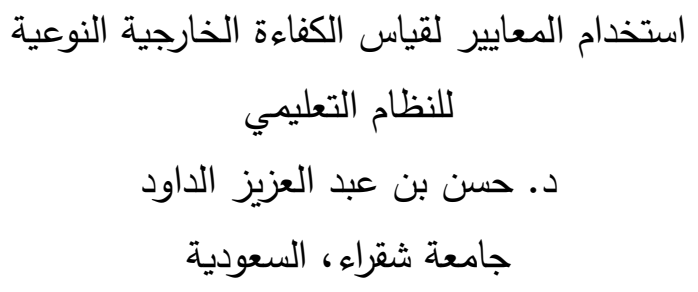 & & \\
\hline \multicolumn{3}{|l|}{ 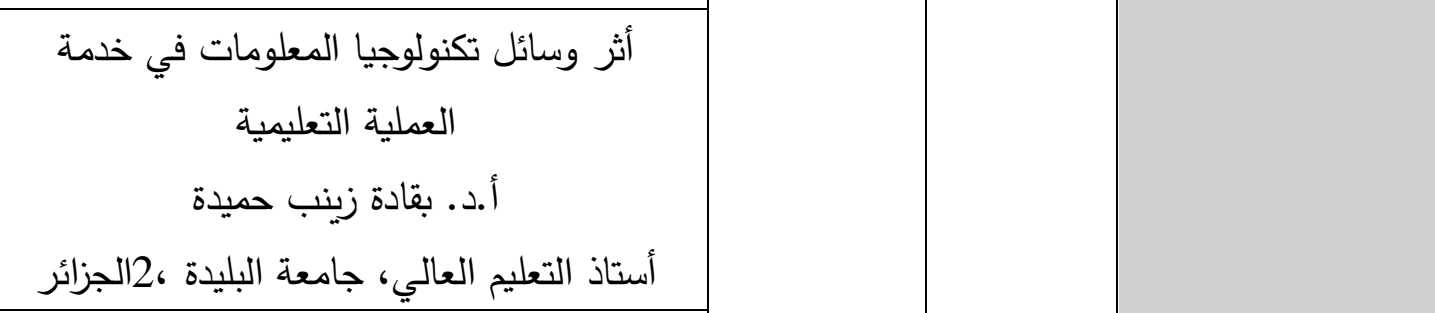 } \\
\hline 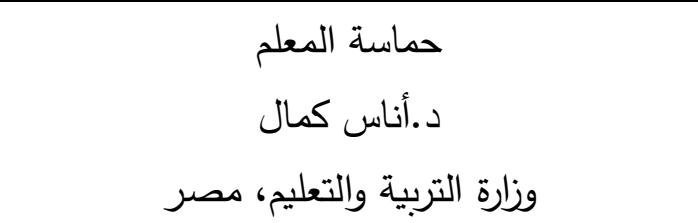 & & \\
\hline \multicolumn{3}{|l|}{ النقابلية للتكيف المهني للمعلمين: التصورات المعلم على إعداد المعلم المتكيف القياس، ودور برامج تدريبة المهنة } \\
\hline 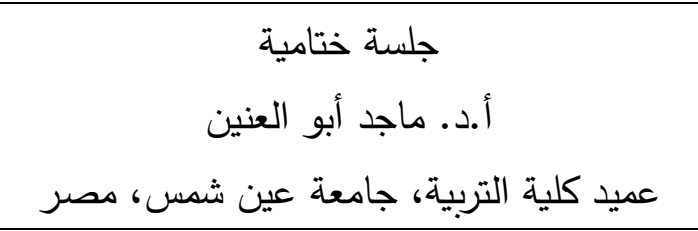 & $\begin{array}{l}\bar{s} \\
\text { 员 }\end{array}$ & •r:ץ • الى • , . . \\
\hline \multicolumn{2}{|l|}{ غذاء } & 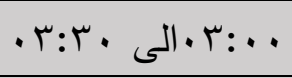 \\
\hline 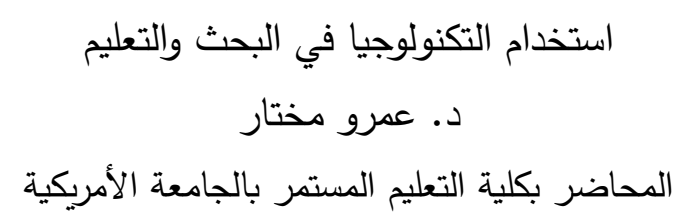 & 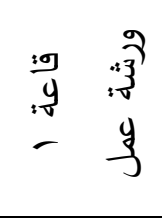 & • ץ:ץ.الى • • . . \\
\hline
\end{tabular}




\section{توصيات المؤتمر}

ا ـ تحقيق التوازن في مناهج التعليم بين القومي، والاقليمي، والعالمي. r. ضرورة اتخاذ إجراءات وقرارات سياسية وتشريعية تنص على جعل التعليم باللغة العربية في جميع المدارس.

r. التحول من ثقافة الحد الأدنى الكافي إلى ثقافة الجودة الثاملة في مخرجات

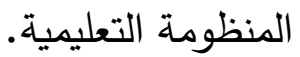
ـ. مراجعة مناهج التعليم وتتقيتها مما لا يتناسب مع متطلبات العصر الحالي. 0. الاسترشاد بالمواثيق واللوائح الخاصة بالهيئات العالمية والتجارب الدولية في تحسين السياسة التعليمية الحالية. T. التركيز على علوم المستقبل في مناهج التعليم.

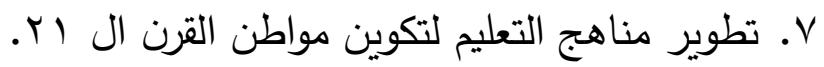
^. الاصدلاح المتمركز حول المؤسسة التعليمية وإعدادها للاعتماد. 9. تبني ثقافة الابداع بدلا من ثقافة الذاكرة في منظومة التعليم. • ا.تتمية المعلمين مهنيا، ورعايتهم اجتماعيا وماديا. 11 ـ التأكيد على تحقيق مبدأ التعليم مدى الحياة. r ا ـ بناء بيئات تعليمية داعمة للتعليم داخل المؤسسات التعليمية. با ـ الاهتمام بتوفير بيئة تعليمية مناسبة لذوي الاحتياجات الخاصة. ع ا ـالاهتمام بالأكاديميات الناشئة في مجال التعليم الفني والتي تتبنى نظام التعليم المزدوج الجامع بين التعليم النظري الأكاديمي والعملي داخل

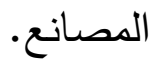

1 ـ تحقيق التكامل بين التعليم الأكاديمي النظري والتعليم الفني. 7 ا ـ الربط بين العملية التعليمية داخل المدارس وبين متطلبات سوق العمل. 


\section{توصيات المؤتمر الدولى الثالث لكلية التربية جامعة عين شمس}

V ا التركيز على إكساب الطلاب الجدارات المهنية والحياتية والتطبيقية التي يحتاج إليها سوق العمل خاصة في مجال التعليم الفني. 1 ا ـاعتبار مرحلة التعليم قبل الجامعي مرحلة تهيئة وإعداد للتعليم الجامعي. 9 1 ا تطبيق مبدأ مركزية التخطيط، ولا مركزية التنفيذ. • r. r. تنويع مصادر تمويل التعليم.

ا Y. تعميم نظام التعليم المتكامل المنظومي بمدارس الجمهورية من مرحلة رياض الأطفال، تشرف عليها كليات التربية مع وزارة التربية والتعليم وتقديم فيها هذه التجربة مع التعديلات اللازمة التي يراها الخبراء والمتخصصين على غرار المدارس اليابانية.

ץ. الاهتمام بتدريب المعلمين داخل كليات التربية حتي يصلوا إلى المستوي الاحترافي المنشود. - مان.

rr.تعزيز قيم الوسطية في نظام التعليم المصري. צ r. تفعيل دور المؤسسات التعليمية لاعم قضايا التماسك الاجتماعي. هץ ـ تعزيز دور التعليم العالي في مواجهة التحديات العالمية. جr. تنمية الوعي الديني ومضاعفة روح الابداع والابتكار للتعليم العالي. rV 1 r. نشر مفهوم الازدهار النفسي بين الطلاب وتتميته. وץ.الاهتمام بالطالب المعلم باعتباره معلم الغد والتركيز علي تتمية الجوانب

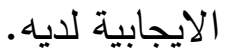

